\title{
PRINCIPIOS RECTORES, LEGISLADOR Y TRIBUNAL CONSTITUCIONAL
}

\author{
Principles governing economic and social policy, \\ legislative power and Constitutional Court
}

\author{
PALOMA BIGLINO CAMPOS \\ Universidad de Valladolid \\ paloma.biglino@uva.es

Amplios sectores reclaman, desde hace tiempo, reformar la Constitución para incluir nuevos derechos sociales. En estos momentos, la modificación de nuestra norma fundamental parece difícil, aunque cada vez sea más urgente asegurar el carácter social de nuestro Estado. Este artículo pretende hacer frente a esta necesidad proponiendo una visión distinta de los principios rectores de la política social y económica que aparecen proclamados en el capítulo tercero del título primero de la Constitución. Este ensayo subraya, en primer lugar, algunas inconsistencias en la visión mantenida por el Tribunal Constitucional acerca de los principios. Sugiere, en segundo lugar, una posible utilización más adecuada de ellos. En efecto, algunos de los principios no imponen cargas financieras a los poderes públicos, sino solo la protección de sectores en situación de desventaja en una relación de carácter horizontal, como ocurre con los trabajadores o consumidores. Por ello, los principios no solo deberían ser utilizados para decidir acerca de la constitucionalidad de las leyes que no cumplen con estos objetivos, sino que, además, el Tribunal Constitucional debería potenciarlos a la hora de interpretar la distribución de competencias y de ponderar los derechos fundamentales que existen en nuestro ordenamiento. 
Palabras clave

Principios rectores de la política social y económica; derechos sociales; justicia constitucional.

\begin{abstract}
Some political forces and a relevant number of constitutional law authors are requiring the reform of the Constitution in order to incorporate new social rights. At this moment, the modification of our supreme norm seems to be difficult, but the need to guarantee the social character of our state appears to be urgent. In order to ensure social right, which are inherent to human dignity, this article proposes a different vision of the principles governing economic and social policy that are enshrined in the third chapter of title one of the Constitution. Firstly, the article highlights some inconsistencies in the interpretation of these principles given by the Constitutional Court. Secondly, the article proposes that the Tribunal use the principles more adequately. In fact, some of the principles do not impose financial cost to public power, but only the protection of sectors that are in a position of disadvantage in horizontal relationships (such as workers or consumers). Consequently, the principles should be used to review the constitutionality of the laws that do not comply with this goal. Furthermore, the Constitutional Court should give more consideration to the principles when it interprets the distribution of competences and ponders the fundamental rights that exist in our constitutional systems.
\end{abstract}

\title{
Keywords
}

Principles governing economic and social policy; social rights; constitutional review. 


\section{SUMARIO}

I. INTRODUCCIÓN. II. LA CONCEPCIÓN MINIMALISTA DE LOS PRINCIPIOS RECTORES DE LA POLIITICA SOCIAL Y ECONÓMICA. III. LOS PRINCIPIOS RECTORES COMO PARÁMETRO DE INCONSTITUCIONALIDAD: 1. La diferente textura de los principios rectores. 2. Los principios como parámetros de invalidez. 3. De lo imposible a lo improbable: la STC 273/2016. IV. LA INTERPRETACIÓN DE LA CONSTITUCIÓN Y DE LA LEY CONFORME A LOS PRINCIPIOS RECTORES: 1. Principios rectores y orden constitucional de competencias. 2. Principios rectores y ponderación en derechos. BiblografíA.

\section{INTRODUCCIÓN}

A principios de año, parecía que la crisis económica que había estallado en 2008 empezaba a remitir. No creo que se pueda afirmar que estuviera definitivamente superada, al menos para la mayor parte de la población. Al margen de los datos macroeconómicos, lo cierto es que los ciudadanos todavía experimentaban las consecuencias derivadas de los recortes en gastos sociales con que se intentó abordar el déficit público. No hace falta entrar en detalle a la hora de describir una situación conocida por todos e ilustrada con precisión por Eurostat. Baste solo con señalar que la tasa de riesgo de pobreza en España, en 2017, seguía siendo una de las más preocupantes de la UE, ya que afectaba a más del $21 \%$ de la población. Además, la desigualdad en la distribución de la renta era todavía muy alta. El grupo compuesto por el $20 \%$ de quienes percibían más ingresos recibió seis veces más de renta que el grupo del $20 \%$ con menos medios 1 .

Las políticas de recortes no han sido ajenas a esta situación. Todavía en 2015, España tenía un gasto total por alumno en instituciones educativas (públicas, concertadas y privadas) de 8432 dólares, inferior al promedio de los países de la OCDE y la UE22 en un $14 \%$ y $12 \%$, respectivamente ${ }^{2}$. Los gastos sanitarios no corrieron mejor suerte, lo que ha sido asunto de actualidad en los últimos meses. Según la Comisión Europea, el gasto per cápita en 2017 era de 2371 euros, esto es, un $15 \%$ por debajo de la media de la UE UE $^{3}$.

Estadísticas sobre pobreza de ingresos disponibles en: https://bit.ly/2zLgGXR.

2 Panorama de la educación. Indicadores de la OCDE 2018. Ministerio de Educación y Formación Profesional. Informe español, p. 44.

3 State of Health in the EU. España. Perfil sanitario nacional 2019. Disponible en: https://bit.ly/2ANDCX0. 
Según las últimas noticias, la República Federal de Alemania cuenta con 33 UCI por cada 100000 habitantes. En España, la proporción es de nueve $e^{4}$.

Cuando parecía que, finalmente, la situación económica empezaba a mejorar y se relajaban las medidas dirigidas a recortar el gasto público, nos hemos encontrado, de manera muy súbita, con el impacto de la pandemia generada por la covid-19. Las acciones destinadas a atajarla tendrán unas consecuencias económicas cuyo alcance es difícil de prever. En el momento de escribir estas páginas todavía es pronto para saber la auténtica dimensión del problema, aunque la paralización de la economía, la necesidad de evitar que las empresas de nuestro país se vayan a la ruina y las ayudas sociales que se han destinado a los sectores afectados hacen sospechar que el impacto va a ser muy superior al que tuvo la quiebra de Lehman Brothers. Así lo ha asegurado, al menos, el FMI, que prevé que las consecuencias del Great Lockdown van a ser las peores desde la Gran Depresión ${ }^{5}$ : para España, vaticina un desplome económico del $8 \%$ y un incremento del paro hasta el 20,8\%. En estas circunstancias es posible que, como ocurrió en 2008, haya sectores partidarios de hacer frente al incremento del déficit recortando gasto público y, más precisamente, prestaciones sociales.

El principio de estabilidad presupuestaria es, desde que entró en vigor el Tratado de Estabilidad, Coordinación y Gobernanza de la Unión Económica y Monetaria, de marzo de 2012, la regla de oro de la eurozona. Poco antes, España había decidido reforzar dicho principio mediante la polémica reforma del art. 135 CE. Estamos, pues, vinculados por partida doble a no gastar mucho más de lo que ingresamos. Pero esto no significa, obligatoriamente, que la crisis que se nos avecina deba ser resuelta con las mismas políticas que se llevaron a cabo durante la anterior crisis económica. España es un Estado social, no solo porque así lo dispone el art. 1.1 CE Constitución, sino porque es también la realidad que impera en nuestro continente desde la Segunda Guerra Mundial. Y son las políticas nacionales las que deciden si cada país va a gastar más en cańones que en mantequilla (Biglino, 2016: 75).

Estas páginas pretenden encontrar argumentos para consolidar esa forma de Estado. Ahora bien, no me parece que el camino a seguir, al menos por el momento, sea una reforma de la Constitución destinada a blindar los derechos sociales. Y ello por diferentes argumentos: en primer lugar, porque no parece que las circunstancias en las que ya nos hallamos y, aún más, en las que nos encontraremos constituyan el ambiente adecuado para debatir sobre el asunto, y, en segundo lugar, porque las fuerzas políticas parecen más

4 García Aller, M. «La paradoja del Fernando Simón alemán y un aviso para España». El Confidencial, 27-4-2020. Disponible en: https://bit.ly/2XfLWHn.

5 Disponible en: https://bit.ly/2B8oN11. 
entretenidas en la descalificación mutua que en tejer acuerdos, al menos en el momento de escribir estas páginas.

El Derecho constitucional es una técnica y, como tal, ha de ser pragmática. En otros momentos he mantenido que debemos empezar la casa por los cimientos y no por el tejado ${ }^{6}$, esto es, que primero deberíamos ponernos de acuerdo sobre lo que debemos reformar y luego debatir acerca de la jerarquía normativa que precisan los nuevos consensos. Pero la salvaguarda del Estado social puede alcanzarse no solo modificando el ordenamiento sino también interpretándolo adecuadamente.

La propuesta de estas páginas consiste en revisitar la concepción de los principios rectores de la política social y económica que hasta el momento ha mantenido no solo buena parte de la doctrina, sino también el Tribunal Constitucional en algunas (quizá sean mayoría) de sus decisiones, y que, grosso modo, puede tildarse de minimalista. No voy a analizar los supuestos en los que el máximo intérprete de la Constitución ha conectado los principios con derechos fundamentales, dado que este asunto no me parece polémico. $\mathrm{Me}$ parece más interesante pasar revista a la concepción dominante en la jurisprudencia del Tribunal Constitucional con la finalidad de poner de manifiesto algunas de sus características y, por qué no decirlo, contradicciones. Posteriormente intentaré demostrar que el Tribunal Constitucional puede hacer un mejor uso de los principios rectores a la hora de velar por la propia fuerza normativa de la Constitución, por el orden constitucional de competencias y por el equilibrio entre derechos y bienes constitucionales.

\section{LA CONCEPCIÓN MINIMALISTA DE LOS PRINCIPIOS RECTORES DE LA POLÍTICA SOCIAL Y ECONÓMICA}

No resulta sencillo reconstruir la jurisprudencia del Tribunal Constitucional con respeto a los principios rectores de la política social y económica dado que, en muchas ocasiones, se utilizan como argumento ad abudantia, esto es, con la finalidad de apuntalar decisiones tomadas en razón de otros fundamentos. La tarea se complica más si tenemos en cuenta que los principios rectores aparecen en sentencias dictadas por dicho órgano en distintos tipos de procesos, como son conflictos de competencias, recursos de amparo o recursos y cuestiones de inconstitucionalidad. Como veremos más adelante, en el primero de estos casos el Tribunal analiza, básicamente, la manera en

6 «Empezar la casa por el tejado». El Pais, 6-12-2019. Disponible en: https://bit. ly/327MQIZ. 
que los principios se proyectan en el orden de competencias, mientras que en el segundo se trata de la relación entre principios y derechos fundamentales. Es claro que, cuando se plantean estos tipos de cuestiones, el enfoque del Tribunal debe ser distinto que cuando se trata de la contradicción de la ley con las normas recogidas en el capítulo tercero del título primero de la Constitución. Hay que tener presente, además, que dichos preceptos versan sobre materias muy dispares (desde la familia a la salud, pasando por la protección del medio ambiente y de los consumidores) y obedecen a diferentes tipos de redacción, ya que pueden contener desde objetivos muy genéricos (como puede ser la promoción del progreso social y económico) hasta preceptos mucho más concretos, que podían parecer facultades subjetivas, como es el caso del derecho a la vivienda.

Ahora bien, no resulta muy complejo identificar los ejes fundamentales de la argumentación del Tribunal porque, a pesar de las diferencias existentes entre los distintos principios y los diversos contextos en los que aparecen, hay ideas que han permanecidos constantes.

Ante todo, el Tribunal recuerda que, como el propio art. 53.3 CE reconoce, no estamos ante derechos subjetivos, dado que solo es posible invocarlos ante la jurisdicción ordinaria de acuerdo con las leyes que los desarrollen ${ }^{7}$. Ahora bien, esto no priva a los principios de naturaleza jurídica. En efecto, el Tribunal suele resaltar que, como establece el precepto que se acaba de citar, tienen un carácter informador de la legislación positiva, la práctica judicial y la actuación de los poderes públicos. No estamos, pues, ante normas meramente programáticas vacías de contenido, sino que, al margen de su mayor o menor generalidad, tienen naturaleza vinculante no solo por mandato del art. $53 \mathrm{CE}$, sino también por el art. $9 \mathrm{CE}^{8}$. En virtud de este carácter, deben estar presentes en la interpretación tanto de las restantes normas constitucionales como de las leyes?.

Uno de los asuntos que más preocupa al Tribunal es la vinculación que imponen sobre el legislador. Al tratar este tema, casi todas las decisiones jurisprudenciales se inclinan por atribuir a dicho poder un amplio margen de configuración a la hora de determinar las medidas más adecuadas para llevar a cabo la plasmación de los principios ${ }^{10}$. El propio Tribunal reconoce que no puede, por ejemplo, interferir en las valoraciones del legislador «con decisiones singularizadas susceptibles de alterar el equilibrio económico financiero del

SSTC 32/1983, FJ 2; 149/1991, FJ 1; 102/1995, FJ 4-7, y 233/2015, FJ 2.

SSTC 14/1992, FJ 11, у 233/2015, FJ 2.

SSTC 19/1992, FJ 11, y 233/2015, FJ 2.

10 SSTC 84/2013, FJ 6, y 233/2015, FJ 2. 
conjunto del sistema» $»^{11}$. El Tribunal no niega que los principios rectores formen parte del parámetro de inconstitucionalidad de las leyes ${ }^{12}$ ni que, en determinadas circunstancias, una norma legal pueda ser considerada inconstitucional por omisión, esto es, por no atender aisladamente considerada el mandato de los poderes públicos (ibid.). Ahora bien, también reconoce que este es un supuesto improbable y «sólo puede entenderse producido cuando es la propia Constitución la que impone al legislador la necesidad de integrar en su texto aspectos no contemplados por ella $»^{13}$.

Un aspecto interesante de este conjunto de aseveraciones es su continuidad en el tiempo. Aunque, como señalaba antes, el Tribunal Constitucional matiza alguna de estas afirmaciones según el asunto sometido a examen, puede afirmarse que esta jurisprudencia se mantiene desde las primeras sentencias sobre los principios rectores, que se remontan a los años ochenta del siglo pasado.

Es, en esta época, cuando encontramos la polémica doctrinal más intensa sobre la eficacia de los principios rectores, que no es ajena al debate ideológico de aquellos ańos sobre la naturaleza de las previsiones sociales contenidas en nuestra norma fundamental (Prada, 2003; Serrano, 1987). El ámbito donde se enmarcan las distintas posturas es la discusión entre quienes entendían la Constitución como programa, que debía ser desarrollado por el legislador, y quienes, de manera distinta, consideraban que la Constitución era, sobre todo, garantía de alternancia en el poder, por lo que era preciso interpretarla de manera que cupieran en ella diferentes políticas, fueran estas socialdemócratas o neoliberales ${ }^{14}$.

En realidad, no eran muchos quienes mantenían que era posible declarar una ley inconstitucional por incumplir los mandatos recogidos en los principios rectores de la política social y económica. Un buen ejemplo es L. Aguiar de Luque, quien no descarta esta posibilidad (1987: 28). También son pocos los que, en el extremo contrario, privan a los principios rectores de la política

\footnotetext{
STC 75/2011, FJ 4.

STC 45/1989, FJ 4.

SSTC 317/1994, FJ 4, y 139/2016, FJ10.

14 Un buen ejemplo de esta concepción es la visión de F. Rubio Llorente, quien, en 1984, afirmaba que «el legislador no es un ejecutor de la Constitución, sino un poder que actúa libremente en el marco de ésta y esta libre actuación requiere en muchos casos (aunque no, claro es, en todos) que el enunciado de esos preceptos constitucionales permita un ancho haz de interpretaciones diversas. No de interpretaciones "jurídicas", sino de interpretaciones políticas, es decir, de diversas maneras de entender el texto constitucional [...]» (Rubio Llorente, 1984: XXI). M. Aragón Reyes, desde la óptica del principio democrático, llega a conclusiones similares (Aragón, 1989: 213).
} 
social y económica de cualquier eficacia jurídica. El mejor ejemplo de estos últimos es, quizá, F. Garrido Falla, quien señala que para que una declaración constitucional tenga naturaleza jurídica no basta con su inclusión en el texto constitucional, sino que es necesario que tenga una estructura lógica de norma jurídica, "es decir, que consista en un mandato, una orden, prohibición o correlativa delimitación de esferas jurídicas entre sujetos, con establecimiento de recíprocas obligaciones y derechos» (1980: 579).

Quizá uno de los autores que dedica más atención al asunto y mantiene una postura muy similar a la del Tribunal Constitucional sea I. de Otto. Dada la influencia que su sistema de fuentes ha tenido en nuestra doctrina, no está de más recordar algunas de sus afirmaciones. Su análisis de los principios rectores enlaza con sus críticas a las normas de programación final. Estas últimas, para el autor, suscitan dos órdenes de problemas: el primero de ellos se sitúa en su propia naturaleza como normas jurídicas, el segundo consiste en su difícil articulación con una noción abierta y, por lo tanto, democrática de Constitución.

Para el autor, la primera dificultad de las normas de programación final no radica en la indeterminación del fin, sino en el hecho de que el contenido del deber ser sea precisamente un fin. Con ello, I. de Otto viene a decir que se alejan de la estructura típica de las normas que, por ejemplo, en materia de derechos fundamentales, condicionan la programación a la presencia de un determinado supuesto de hecho. En los principios, por el contrario, «ni se define el supuesto de hecho, cuándo hay que actuar, ni se prescribe el contenido de la acción, qué hay que actuar, sino que tan sólo se indica el fin que hay que perseguir». Con ello, no es posible identificar la conducta que realizar por quien debe perseguir dicha meta, por lo que dejan al destinatario un amplio margen de discrecionalidad para elegir los medios adecuados al fin. La programación final es, pues, un cuerpo extraño, subordinado y de dificilísimo manejo dogmático (1989: 43-44).

Este reproche a las normas de programación final presupone, evidentemente, una concepción kelseniana del ordenamiento jurídico, porque fue el autor austríaco quien, ya en Berkeley, definió la regla jurídica como un juicio hipotético que enlaza ciertas consecuencias a determinadas condiciones (Kelsen, 1995: 53). Ahora bien, la definición de Kelsen no se refiere a las normas jurídicas, sino, como se acaba de señalar, a las reglas. Y, como es de sobra conocido, el derecho no es solo lo que se alega ante los tribunales, sino que también resulta integrado por principios y valores.

Esto explica que, aún en el marco de los derechos fundamentales, haya mandatos al legislador que no contienen el grado de definición que I. de Otto les atribuye, sino que solo imponen objetivos al legislador sin decirle ni cuándo 
ni qué tiene que hacer. Buenos ejemplos son el art. 20.4 CE, según el cual «la ley limitará el uso de la informática para garantizar el honor y la intimidad personal y familiar de los ciudadanos y el pleno ejercicio de sus derechos», o el art. 20.3 CE, que dispone que «la ley regulará la organización y el control parlamentario de los medios de comunicación social dependientes del Estado o de cualquier ente público y garantizará el acceso a dichos medios de los grupos sociales y políticos significativos, respetando el pluralismo de la sociedad y de las diversas lenguas de España». Y, de otro lado, hay principios rectores que contienen un grado más alto de precisión porque determinan en mayor medida el contenido de la futura norma legislativa. Sirva como ejemplo el art. 39.2 CE, según el cual la ley deberá posibilitar la investigación de la paternidad.

No parece, pues, que el argumento puramente lógico sirva para privar a los principios rectores de textura jurídica. Esto es, no pueden equipararse, como sin embargo hacía I. de Otto, a esas determinaciones finales, tales como el «bien común» y la "paz en la tierra», que explican la expansión del poder del monarca en la gestación del Estado moderno (1989: 44). Es cierto que los principios no pueden invocarse ante los tribunales como si fueran derechos subjetivos hasta que no hayan sido desarrollados por el legislador, pero esta imposibilidad no deriva de su propia textura jurídica, sino de la voluntad del constituyente, quien expresamente lo excluyó en el art. 53.3 CE.

El segundo argumento que I. de Otto utiliza en contra de las normas de programación final enlaza con el carácter abierto que debe atribuirse a la Constitución y que, para el autor, es la mejor defensa de su carácter normativo. Si se concibieran como programa se pondría en cuestión la estabilidad de la norma fundamental, se limitaría la libertad de configuración del legislador y se incrementaría antidemocráticamente la discrecionalidad del juez. Todo esto significaría "poner en peligro el propio Estado de Derecho, al introducir un elemento de incertidumbre respecto de lo que es conforme o contrario a la Constitución».

Es evidente que, a partir de estas premisas, no resulta sencillo explicar la presencia de los principios rectores en nuestra norma fundamental.

De un lado, I. de Otto reconoce que, en virtud de la supremacía de la Constitución, los principios son normas jurídicas que obligan a todos los poderes públicos. Al menos hipotéticamente, es perfectamente posible, pues, examinar a la luz de estas normas la constitucionalidad de las leyes y de cualquier norma o acto del poder público. Ahora bien, como son normas de programación final, dicho enjuiciamiento debe estar limitado. Para respetar la libre configuración del legislador, el Tribunal Constitucional debe ceñirse a sancionar los supuestos en que la ley resulte manifiesta y claramente 
contraria al fin prescrito (1989: 48). A partir de estas estas precauciones, el autor termina reduciendo la eficacia de los principios a ser una fuente de interpretación. En efecto, como seńala el art. 53.3 CE, los principios rectores solo pueden ser alegados ante la jurisdicción ordinaria de acuerdo con lo que dispongan las leyes que los desarrollen, lo que indica claramente que las pretensiones de obtener alguno de los bienes a que se refieren solo podrán prosperar en la medida en que estén reconocidas también en una ley. De esta manera I. de Otto termina concluyendo: «No cabrá, por tanto, que en ausencia de norma legal un tribunal declare el derecho de alguien a una vivienda digna o que sancione un atentado contra el medio ambiente. Al excluir esta posibilidad la Constitución pretende evitar que los tribunales se sitúen en la posición del legislador».

En definitiva, parece que, para I. de Otto, los principios rectores han de ser tenidos en cuenta por todos los tribunales, incluido el Constitucional, como criterios interpretativos, tanto de la Constitución como de la legislación ordinaria. Como ejemplo señala que el principio de igualdad de los hijos ante la ley con independencia de su filiación sirve para interpretar el principio general de igualdad del art. $14 \mathrm{CE}$, así como la legislación correspondiente (1989: 49).

Hay muchas coincidencias, pues, entre las afirmaciones de I. de Otto y la jurisprudencia del Tribunal Constitucional. Es cierto que la obra de I. de Otto se apoya en otros destacados constitucionalistas que habían hablado del carácter abierto y democrático de la Constitución, como F. Rubio Llorente o M. Aragón. Pero es, quizá, el que fuera letrado del Tribunal Constitucional quien dedica mayor atención a la posición de los principios en la norma fundamental.

No voy a poner en tela de juicio la noción de Constitución que se acaba de mencionar, dado que me parece la única posible en un sistema democrático. Tampoco las consecuencias que implica a la hora de limitar el papel del juez constitucional con respecto al legislador. Sin embargo, creo preciso llevar a cabo algunas reflexiones acerca de la naturaleza de los principios rectores, porque me parece que considerarlos como normas meramente interpretativas no es coherente con la propia concepción democrática de constitución.

Dicho carácter no radica solo en atribuir a la Constitución una naturaleza abierta que permita políticas de diferente signo. Está también en su origen, como manifestación del poder constituyente del pueblo expresado a través de sus representantes. Cuando se elabora una constitución democrática, se expresa un consenso, fundamental y fundante, acerca de quién manda, cómo se manda y para qué se manda. Y esto, evidentemente, limita la acción del legislador y del resto de los poderes públicos. El art. 1.1 CE define nuestro 
Estado no solo como democrático, sino también como social y de derecho. No parece que la cláusula de Estado social tenga unas connotaciones jurídicas distintas a las demás notas que caracterizan nuestra forma de organización política. Podía ser así en el período de entreguerras, cuando se elaboran la Constitución de Weimar o la espańola de 1931, pero me parece que, desde entonces, se ha avanzado un buen trecho. El Estado social ya no es un pío deseo que construir, sino una realidad generalizada en los países occidentales. Es cierto que experimenta fallos, retrocesos o contradicciones: en definitiva, que no siempre es una realidad completa. Pero esto no atribuye a dicha definición del Estado una naturaleza distinta al Estado democrático o al Estado de derecho, cuyas quiebras, contradicciones y retrocesos son igual de manifiestos. Frente a lo afirmado por I. de Otto, el Estado social no es, pues, un programa ni un orden que los poderes del Estado han de «realizar» o «desarrollar». Es, como las otras definiciones constitucionales, un deber ser, porque es norma jurídica. Tampoco el Estado de derecho o el Estado democrático son perfectos, pero eso no desautoriza a la Constitución ni nos permite descalificarla por no describir lo que sucede en realidad.

Si la Constitución es norma jurídica es porque el deber ser que incorpora se impone a todos los poderes constituidos, incluido el legislador. El Estado social también es Constitución, por lo que también delimita la acción política.

En contra de esta afirmación, que por simple se olvida, se ha argumentado que los derechos sociales tienen una textura distinta a la del resto de los derechos, porque tienen repercusión presupuestaria. Esta argumentación no parece de recibo, al menos hoy día. En primer lugar, porque hay derechos que no son sociales y, sin embargo, tienen repercusión presupuestaria, como es la tutela judicial efectiva o la libertad y seguridad personal. El primero implica la necesidad de mantener toda la organización judicial mientras que el segundo obliga a sostener a las fuerzas y cuerpos de seguridad, garantes frente a terceros no solo de nuestra libertad, sino también de nuestra vida, integridad personal y propiedad, entre otros derechos. Pero, además, y en segundo lugar, porque hay derechos sociales que no exigen un desembolso económico por parte de los poderes públicos, sino que les imponen intervenir normativamente en las relaciones sociales para equilibrar la balanza en favor de la parte que se encuentre en situación de desventaja. Esto es lo que sucede, por ejemplo, cuando se regulan los derechos de los trabajadores frente a los empresarios en el seno de las relaciones laborales o cuando se protege a los consumidores o usuarios frente a los ofertantes de bienes o servicios.

Los principios rectores no son derechos subjetivos, porque el art. 53.3 CE les priva de este carácter, al señalar que solo podrán ser alegados ante la jurisdicción ordinaria de acuerdo con las leyes que los desarrollen. Pero esto 
no los rebaja a simples preceptos morales sujetos únicamente al control político. Al contrario de lo que afirmaba A. V. Dicey, el derecho constitucional no se reduce a las normas que son aplicadas por las cortes de justicia (1987: 24). Son preceptos jurídicos, que, aunque dotados de menor eficacia que las reglas, son siempre derecho. En definitiva, como afirma el propio texto constitucional, son principios.

La teoría general ha elaborado muchos criterios para distinguir valores, principios y reglas. Quizá la más adaptada a nuestro ordenamiento sea la diferenciación que, en su momento, elaboró M. Aragón Reyes (1988: 23-27). Para el autor, los principios, a diferencia de los valores, no solo sirven para interpretar normas, sino que también pueden alcanzar "proyección normativa» tanto por obra del legislador como del juez. Mientras que los valores solo pueden ser convertidos en norma por el Parlamento, en el caso de los principios el juez puede extraer de ellos la regla concreta. Con ello no suplanta al legislador, sino que cumple las prescripciones dictadas por el propio constituyente aplicando el derecho condensado. Para marcar la diferencia entre valores y principios, M. Aragón se sirve de la distinción efectuada por J. Stick entre lo «impredictible» de los valores (que se corresponde con la libre opción jurídica) y lo «indeterminado» de los principios (que se corresponde con la discrecionalidad jurídica). A esto añade:

Los valores son enunciados que podríamos situar en el campo de la impredictibilidad, en cuanto que su proyección normativa se rige por criterios subjetivos (amplio margen, pues, de libertad) que la oportunidad política suministra. Los principios son enunciados que pertenecerían al campo de la indeterminación, en cuanto que su proyección normativa se rige por criterios objetivos que el propio Derecho proporciona (1988: 25).

Pues bien, a diferencia de lo que a veces parece, los principios rectores no son meros valores y, por ello, no quedan reducidos a ser normas meramente interpretativas. Desde luego, pueden ser utilizados por los jueces dado que no solo deben informar la legislación positiva, sino también la práctica judicial, incluida la del Tribunal Constitucional. Ahora bien, cuando la Constitución señala que solo podrán ser alegados de acuerdo con las leyes que los desarrollen, la norma fundamental únicamente excluye que, a partir de su dicción constitucional, puedan reputarse derechos subjetivos, esto es, reglas que puedan hacerse valer ante los jueces ordinarios. Esto no implica, sin embargo, que no puedan alegarse ex constitutione ante el Tribunal Constitucional para impugnar la constitucionalidad de la ley ni que dicho órgano deba ignorarlos al hacer el juicio de validez. 
Es cierto que el legislador goza de libertad a la hora de llevar a cabo sus propias políticas. También es verdad que el Tribunal Constitucional no puede vulnerar dicha libertad imponiendo su propia visión subjetiva frente a la sostenida por el único órgano que representa a todo el pueblo en su conjunto. Pero los principios rectores son un límite dotado de la máxima jerarquía que, como muchos otros preceptos constitucionales, transforma esa libertad en discrecionalidad. El legislador puede hacer lo que considere oportuno, pero nunca vulnerarlos.

I. de Otto tenía razón, pues, al señalar que el Tribunal Constitucional puede declarar inconstitucional una ley cuando esta resulte manifiesta y claramente contraria al fin prescrito por los principios. También tiene razón M. Aragón cuando señala que los casos difíciles, en los que no existe una regla de derecho, por lo que el juez resulta obligado a extraerla del principio, son raros. Ahora bien, lo improbable no siempre es imposible. Y, sobre todo, como veremos a continuación, no todos los principios rectores de la política social y económica imponen el mismo grado de vinculación.

\section{LOS PRINCIPIOS RECTORES COMO PARÁMETRO DE INCONSTITUCIONALIDAD}

\section{LA DIFERENTE TEXTURA DE LOS PRINCIPIOS RECTORES}

Antes se ha señalado que el Tribunal Constitucional siempre ha reconocido que el capítulo III del título I es Constitución, por lo que no descarta que puedan utilizarse para medir la invalidez de una ley. Ahora bien, también afirma que no es posible declarar la inconstitucionalidad por omisión, dado que este tipo de decisiones vulneraría la libre configuración del legislador. Esta afirmación aparece, a veces, como un mantra que se repite en las circunstancias más diversas, por lo que resulta, de por sí, intrigante. No está de más, pues, analizarla con cierto espíritu crítico.

La principal preocupación que suscita esta afirmación es su generalidad. No parece posible, en efecto, deducir las mismas consecuencias de la infracción de todos los principios porque no todos son iguales.

El diverso contenido de los principios rectores de la política social y económica ha sido objeto de muchos análisis. Ahora bien, el que mayor repercusión ha tenido y que sigue influyendo en la doctrina es el que realizó J. J. Campo a finales de los ańos noventa (1999: 128 y ss.). El autor distinguía entre normas programáticas, a las que atribuía un mero valor informador, $\mathrm{y}$ otros enunciados normativos, que podían consistir en mandatos de legislar, normas de igualdad 
y garantías institucionales. Ahora bien, también es posible clasificar los principios rectores según su mayor o menor grado de indeterminación.

Hay, en efecto, previsiones muy genéricas que imponen a los poderes públicos actividades que podemos considerar de fomento en áreas como son la cultura, la ciencia, la investigación científica, la juventud, el ocio, la educación física y deporte, protección de la juventud, etc. Hay otros principios que, sin embargo, tienen mucho mayor grado de determinación, como sucede, por ejemplo, cuando se impone a los poderes públicos garantizar la suficiencia económica a los ciudadanos de la tercera edad, mediante pensiones adecuadas y periódicamente actualizadas (art. $50 \mathrm{CE}$ ) o regular la utilización del suelo de acuerdo con el interés general para impedir la especulación (art. $47 \mathrm{CE}$ ).

He querido elegir estos dos ejemplos para demostrar que, aunque el grado de determinación de estos principios es similar, varían claramente en el tipo de obligación que imponen. Es evidente que los dos están dirigidos a los poderes públicos, pero mientras el primero exige un objetivo con clara repercusión presupuestaria, el segundo impone una actuación diferente. No obliga a los poderes públicos a poner a disposición de los ciudadanos una prestación, sino que les obliga a llevar a cabo una actividad mediadora entre los intereses generales y los particulares de los propietarios del suelo, destinada a salvaguardar el bien común.

En realidad, pocos principios rectores imponen una actividad prestacional que pueda depender directamente de la disponibilidad de recursos: junto con el art. $50 \mathrm{CE}$ antes citado, sobre las pensiones, destacan el art. 43 $\mathrm{CE}$, que obliga a organizar y tutelar la salud pública a través de prestaciones y servicios necesarios; el art $41 \mathrm{CE}$, que impone un régimen público de Seguridad Social que garantice la asistencia y prestaciones suficientes ante situaciones de necesidad, especialmente en el caso de desempleo, y el art. $49 \mathrm{CE}$, que exige políticas destinadas al tratamiento, rehabilitación e integración de las personas afectadas por discapacidades físicas, sensoriales o psíquicas.

Una parte importante de los principios, sin embargo, obliga a los poderes públicos a llevar a cabo una intervención en las relaciones sociales que no tienen coste económico directo para las arcas públicas, sino que exige una regulación destinada a limitar el desequilibrio entre las partes de una determinada relación jurídica, como sucede, por ejemplo, en las relaciones laborales, cuando se impone a los poderes públicos garantizar el descanso necesario de los trabajadores, mediante la limitación de la jornada laboral o las vacaciones periódicas retribuidas (art. 40.2 CE); en las relaciones entre consumidores y ofertantes de bienes y servicios, cuando se impone a los poderes públicos la protección de la seguridad, salud y legítimos intereses económicos de los primeros (art. 51.1 CE), y en las relaciones familiares. En este caso, el art. $39 \mathrm{CE}$ 
también se pone de parte del más débil, ya que asegura la protección integral de los hijos, con independencia de su filiación, y de las madres, cualquiera que sea su estado civil.

En este tipo de preceptos, de carácter «horizontal», los principios suelen ser, además, bastante más precisos. No solo se reconocen derechos, aunque sean aparentes, en la terminología de J. J. Campo, sino que, además, imponen a la ley un contenido concreto. Así, por ejemplo, obligan al legislador a posibilitar la investigación de la paternidad (art. $39 \mathrm{CE}$ ), a establecer sanciones penales o, en su caso, administrativas para quienes violen lo dispuesto en materia de medio ambiente (art. 45.3 CE), y a regular la utilización del suelo de acuerdo con el interés general para impedir la especulación y permitir que la comunidad participe en las plusvalías que genere la acción urbanística de los entes públicos (art. $47 \mathrm{CE}$ ).

El capítulo tercero del título primero recoge, pues, las dos formas de intervención pública que caracteriza al Estado social, a la que antes se hacía referencia. Como se acaba de señalar, los principios no solo requieren de los poderes públicos prestaciones directas, sino, además, una actuación destinada a conseguir mayor igualdad, formal y sustantiva. La Constitución, con ello, no recoge objetivos sociales revolucionarios. Ya en 1978, los constituyentes alcanzaron consensos a la hora de elevar a la norma fundamental compromisos que ya integraban el ordenamiento jurídico o que, aunque todavía no se hubieran plasmado legislativamente, se integraban en el ideario de las fuerzas políticas que pactaron la norma fundamental.

Es evidente que la coyuntura económica puede afectar, como ha afectado, a las prestaciones sociales. En estos casos, el carácter vinculante de los principios es menor, porque los poderes públicos no pueden sacar recursos de donde no los hay ni el Tribunal Constitucional puede alterar partidas presupuestarias. Eso no significa que dicho órgano pueda aceptar cualquier tipo de retroceso: es cierto que las conquistas sociales no son irreversibles, sino que dependen de las posibilidades reales (Rodríguez de Santiago, 2018: 1491); ahora bien, hay mínimos que los principios deberían imponer a los poderes públicos y que se deberían garantizar (Ponce, 2017: 79), a menos que el legislador demostrase razonablemente la imposibilidad de hacerlo. Cuando el principio consiste en una prestación directa con contenido económico, la libertad de configuración es mayor y, como veremos más adelante, ha de ser tenida en cuenta por el máximo intérprete de la Constitución, no solo cuando se trata del Parlamento estatal sino también, como veremos más adelante, cuando se trata de los autonómicos.

En el segundo de los casos analizados, esto es, cuando se trata de regular relaciones entre particulares, la tarea del Tribunal Constitucional no 
experimenta tantas limitaciones. Es verdad que la regulación de estas relaciones horizontales se resiente también de la coyuntura económica porque, en determinados momentos, la quiebra de un sector empresarial puede poner en peligro otras metas impuestas a los poderes públicos, como es la política de pleno empleo. Pero, como se acaba de mencionar, los principios son en este caso mucho más concretos porque el contenido que imponen a las leyes es más preciso. En realidad, no estamos ante normas habilitadoras, que permitan al legislador limitar derechos, como la propiedad privada, o la libertad de empresa; son contenidos que el legislador ha de tener en cuenta a la hora de regular una determinada relación jurídica. El legislador podrá aumentar o disminuir la jornada laboral, pero no suprimir cualquier limitación a esta; podrá disponer sobre las vacaciones retribuidas, pero no dictar una legislación que permita al empresario suprimirlas o reducirlas de manera injustificada.

Al dictar sentencia en estos temas, el Tribunal Constitucional debería tener en cuenta que no se trata solo de proteger la libertad de configuración del legislador, sino también el pacto constituyente. En caso de que tolerara que determinadas mayorías políticas incumpliesen claramente lo dispuesto en la norma fundamental, no solo minaría la fuerza pasiva de la norma que debe salvaguardar, sino que, además, propiciaría que su tolerancia hacia determinadas políticas se interpretase como una forma de intervención en favor del más fuerte. En estos asuntos, anteponer la libertad del legislador a lo dispuesto en la Constitución no solo pondría en cuestión el carácter vinculante de la Constitución, sino también la legitimidad del propio Tribunal.

\section{LOS PRINCIPIOS COMO PARÁMETROS DE INVALIDEZ}

Como se acaba de señalar, es posible deducir reglas de los principios, aunque la capacidad del Tribunal para llevar a cabo esta operación difiere según el grado de determinación de los propios principios. Otro asunto es el tipo de fallo que, en caso de que se aprecie la invalidez, puede dictar el Tribunal Constitucional.

Como pudimos analizar en el segundo apartado de estas páginas, el Tribunal Constitucional no excluye, pero ve sumamente improbable, que la infracción de un principio rector lleve a la inconstitucionalidad por omisión. Conviene analizar con más detalle el argumento, expuesto, por ejemplo, en la STC 139/2016. El FJ 10 textualmente afirma:

[...] «la naturaleza de los principios rectores de la política social y económica que recoge el Capítulo III del Título I de nuestra Constitución hace improbable que 
una norma legal cualquiera pueda ser considerada inconstitucional por omisión, esto es, por no atender, aisladamente considerada, el mandato a los poderes públicos y en especial al legislador, en el que cada uno de esos principios por lo general se concreta" (STC 45/1989, de 20 de febrero, FJ 4), de manera que esa inconstitucionalidad por omisión «sólo puede entenderse producida cuando es la propia Constitución la que impone al legislador la necesidad de integrar su texto en aspectos no contemplados por ella» (STC 317/1994, de 28 de noviembre, FJ 4).

Pocas veces se ha cuestionado esta afirmación que, en casos de disensión en el Pleno del Tribunal, no solo aparece recogida en la sentencia sino también, a veces, en los votos particulares ${ }^{15}$. Y, sin embargo, es posible poner en tela de juicio algunos de sus extremos.

Así, en primer lugar, cabe advertir que la última frase del párrafo citado no añade demasiada precisión a la difícil tarea de delimitar los casos en que es posible declarar la inconstitucionalidad por omisión. Quizá por motivos de redacción no es sencillo deducir qué quiere decir el Tribunal cuando señala que solo cabe declarar la inconstitucionalidad por omisión «cuando es la propia Constitución la que impone al legislador la necesidad de integrar su texto en aspectos no contemplados por ella». Es claro que el texto al que se refiere la frase es el del legislador, y no el de la Constitución, porque el Tribunal no puede esperar que el Parlamento integre en la Constitución aspectos que la propia Constitución no contempla. Si esta es la interpretación gramatical correcta, podría afirmarse que el incumplimiento de todos los principios rectores puede motivar la inconstitucionalidad por omisión, ya que todos ellos imponen al legislador metas, fines, objetivos y regulaciones específicas no contemplados por la propia norma fundamental, sino diferidos, precisamente, a la ley.

En segundo lugar, cabe señalar que una ley puede resultar inválida no porque omita los mandatos recogidos en el capítulo tercero del título primero, sino, simplemente, porque los contradiga. En efecto, como se ha analizado, los principios rectores establecen objetivos y fines, pero a veces también precisan el contenido que la legislación debe recoger. En caso de que una ley disponga manifiestamente en contra de dichas previsiones no hay, en puridad, omisión, sino mera vulneración de lo dispuesto por el constituyente.

Al contrario de lo que cabría suponer en un principio, no es tan difícil que este supuesto se produzca en la realidad. Podría, por ejemplo, haber sido

15 Sirva, como ejemplo, el voto particular formulado por el magistrado F. Valdés Dal-Ré a la STC 118/1019, ap. 10. 
el supuesto que dio lugar a la STJUE en el caso $A z i z^{16}$. El hecho de que la normativa espańola, en un procedimiento hipotecario de ejecución, no permitiese ni que el afectado formulara motivos de oposición ni que el juez adoptara medidas cautelares (como la suspensión del procedimiento) quizá no fuera una infracción del derecho a la tutela judicial o del derecho a la vivienda ${ }^{17}$, pero, desde luego, podía entenderse como una infracción de lo dispuesto en el art. $51 \mathrm{CE}$, que impone proteger, mediante procedimientos eficaces, los legítimos intereses económicos de los consumidores. Y esa infracción no estaría provocada por lo que la norma omite (o no dice), sino por lo que dice.

\section{DE LO IMPOSIBLE A LO IMPROBABLE: LA STC $273 / 2016$}

La identificación entre inconstitucionalidad e inconstitucionalidad por omisión seguramente obedece a la cautela del Tribunal Constitucional a la hora de dictar sentencias aditivas, dado que, si ańade contenidos a la ley, corre el riesgo de que se le acuse de usurpar el papel del legislador, imponiendo su opinión frente a la decisión de la mayoría parlamentaria. Ahora bien, en el caso de los principios rectores no toda inconstitucionalidad es por omisión, como se acaba de decir. Y, además, ha habido algún caso en el que el Tribunal Constitucional ha hecho lo que, en principio, excluye hacer, esto es, declarar la inconstitucionalidad por omisión del mandato incluido en un principio rector y dirigir un llamamiento al legislador para incluir en la ley contenidos impuestos por los principios. Me refiero a la STC 273/2005, decisión que pone de manifiesto cómo lo que, a primera vista parece imposible, es más que probable.

La sentencia es el resultado de una cuestión de inconstitucionalidad en la que una audiencia provincial eleva sus dudas acerca del párrafo primero del art. 133 del Código Civil, en la redacción que dicho precepto tenía desde 1981. Dicho artículo reservaba la acción de filiación no matrimonial, cuando faltara posesión de estado, exclusivamente al hijo o a sus herederos. El juicio principal era resultado de una acción de filiación presentada por un varón, quien también reclamaba el derecho a la patria potestad y el establecimiento del régimen de visitas sobre un menor nacido de su relación con la otra parte procesal.

Aunque la Audiencia pregunta al Tribunal Constitucional si el precepto mencionado, al atribuir legitimación únicamente al hijo y excluir a los progenitores, vulnera el principio de igualdad, el derecho a la tutela judicial y el

16 C-415/11, de 14 de marzo de 2013, ECLI:EU:C:2013:164.

17 ATC 113/2011, por ejemplo. Sobre este asunto, Medina Guerrero, 2015: 261-282. 
art. 39.1 y 2 CE, el Tribunal funda su decisión, principalmente, en el principio de libre investigación de la paternidad. Es cierto que dicho órgano aprecia que ha existido una violación del art. $24 \mathrm{CE}$ porque, con una visión instrumental del derecho recogido en dicho precepto, declara que el art. 133.1 del Código Civil impone restricciones innecesarias a la tutela judicial. Ahora bien, la decisión gira en torno a los deberes que impone el art. 39.2 CE, dado que este es el bien constitucional en juego ${ }^{18}$.

El Tribunal Constitucional estima que la privación al progenitor de la posibilidad de reclamar una filiación no matrimonial en los casos de falta de posesión de estado no resulta compatible con el mandato del art. 39.2 CE ni, por ello, con el derecho a la tutela judicial efectiva en su vertiente de acceso a la jurisdicción. En efecto, «la investigación de la paternidad no puede quedar reducida a un derecho del hijo, con exclusión de toda iniciativa por parte de los progenitores, pues también a éstos alcanza un interés en el conocimiento de la verdad biológica» ${ }^{19}$.

Desde estas páginas no es posible entrar en el fondo del asunto, sino que tan solo merece la pena señalar que la decisión resultó muy polémica, dado que dividió por mitad al pleno. Me parece más interesante analizar el fallo, que declara inconstitucional el art. 133.1 CC «en cuanto impide al progenitor no matrimonial la reclamación de la filiación en los casos de inexistencia de posesión de estado». El Tribunal reconoce que, en el supuesto sometido a examen, no es posible una interpretación conforme a Constitución del art. 133.1 CC porque ello supondría «ignorar o desfigurar el sentido de los enunciados legales meridianos» $»^{20}$. Como «la razón de la inconstitucionalidad del precepto reside no en determinación textual alguna de este, sino en su omisión", opta por una declaración de inconstitucionalidad, pero sin nulidad.

Siempre según el Tribunal, declarar la nulidad del art. 133.1 CC generaría un vacío normativo no deseable. Expulsar del ordenamiento la regla legal que, en ausencia de posesión de estado, otorga al hijo la legitimación para reclamar la filiación no matrimonial, además de no reparar la inconstitucionalidad, «dañaría, sin razón alguna, a quienes ostentan [...] una acción que no merece tacha alguna de inconstitucionalidad». Por este motivo, el Tribunal termina con una apelación al legislador. Debe ser este «el que regule con carácter general la legitimación de los progenitores para reclamar la filiación no matrimonial en los casos de falta de posesión de estado». Aunque expresamente el Tribunal reconoce la libertad de configuración de la que goza el

\footnotetext{
FJ 5.

FJ 7.

20 FJ 8.
} 
legislador, así como su «específica legitimidad democrática», le impone incluir, además, «los requisitos que se estimen pertinentes para impedir la utilización abusiva de dicha vía de determinación de la filiación, siempre dentro de los límites que resulten respetuosos con el derecho a la tutela judicial efectiva».

Como era de esperar, tres de los seis magistrados que presentan votos particulares critican la decisión del pleno por imponer un criterio contrario al seguido por el legislador. En opinión de los dichos magistrados, la reforma del Código Civil operada en 1981 pretendía, precisamente, acomodar las acciones de filiación a los principios y valores constitucionales. Además, desde esa modificación, los progenitores contaban con las acciones de reconocimiento previstas en el propio Código. Ampliar la legitimación a los progenitores para la reclamación judicial de la filiación puede ser más acorde a la evolución de la sociedad, pero ello no significa que esa nueva normativa resulte exigida por la ley de leyes.

En definitiva, no parece que, en determinados supuestos, el Tribunal tenga reparo a la hora de salvaguardar principios rectores de la política social y económica. En la sentencia analizada no solo declara la nulidad (como ya había ocurrido en la STC 138/2005), sino que lo hace por omisión e indicando al legislador el contenido que debe tener la ley. Es cierto que, formalmente, el Tribunal Constitucional recurre a una violación del art. $24 \mathrm{CE}$. Ahora bien, la invocación del precepto es meramente instrumental, dado que difícilmente puede deducirse de él un contenido tan concreto como es una acción judicial que, por lo demás, ya estaba prevista en el ordenamiento. El defecto en virtud del cual se decide la inconstitucionalidad de la norma es, en realidad, una visión muy generosa de las obligaciones impuestas por el art. 39.2 CE, precepto que, recordemos, se limita a requerir que la ley posibilite la investigación de la paternidad. En la sentencia analizada, el Tribunal añade al derecho del hijo, que ya estaba recogido en el Código Civil, el derecho de los padres.

No parece necesario entrar a valorar el acierto o desacierto del fondo de esta decisión. Conviene, sin embargo, resaltar que en esta ocasión el Tribunal parece alejarse del criterio general que, tantas veces, había exigido para declarar la inconstitucionalidad por omisión, esto es, que la propia Constitución imponga al legislador la necesidad de integrar su texto en aspectos no contemplados por ella. En el caso analizado, el Tribunal ha ido bastante más allá de dicho criterio al interpretar que el art. 39.2 CE no solo impone que el legislador posibilite la investigación de la paternidad, sino que incorpore la legitimación de los progenitores.

Este argumento no vale para descalificar la sentencia analizada, sino para poner de manifiesto que el criterio del Tribunal no es siempre el mismo. Hay ocasiones, como la que acabamos de ver, en que dicho órgano hace lo que, en términos generales, parece poco proclive a hacer. El ejemplo aportado 
sirve, pues, para pedir más claridad al Tribunal a la hora de proclamar fórmulas generales y, sobre todo, para que no considere excepcional la posibilidad de declarar inconstitucionales (por omisión o por mera contradicción) aquellas leyes que vayan en contra de principios rectores.

El caso analizado sirve, además, para confirmar los criterios expuestos en páginas precedentes a la hora de distinguir el grado de vinculación que los principios imponen al legislador y las circunstancias en las que su incumplimiento puede originar la invalidez. Se trata, en efecto, de una previsión muy concreta recogida en el art. 39.2 CE y que, además, regula relaciones horizontales. La inconstitucionalidad por omisión no llevó al Tribunal a imponer al legislador medidas con repercusiones presupuestarias, sino tan solo llevar a cabo una nueva regulación jurídica de relaciones horizontales.

\section{LA INTERPRETACIÓN DE LA CONSTITUCIÓN Y DE LA LEY CONFORME A LOS PRINCIPIOS RECTORES}

Antes se señalaba que el Tribunal Constitucional atribuye a los principios una eficacia interpretativa de la Constitución y del resto del ordenamiento jurídico. Ahora bien, esta afirmación, que a primera vista parece pacífica, no deja de suscitar algunas dificultades, principalmente en dos ámbitos: el primero es el orden constitucional de competencias, el segundo son los derechos fundamentales.

\section{PRINCIPIOS RECTORES Y ORDEN CONSTITUCIONAL DE COMPETENCIAS}

La manera en que el Tribunal aborda la influencia de los principios rectores en el primero de estos ámbitos es, en principio, respetuosa tanto con los propios principios como con las competencias que corresponden a las entidades territoriales. El criterio principal que reitera en su jurisprudencia consiste en afirmar que los principios rectores no constituyen títulos competenciales autónomos, sino un mandato o directriz constitucional que ha de informar la actuación de los poderes públicos ${ }^{21}$. Constituyen, pues, preceptos «neutros», no aptos para atribuir competencias ni para decantarse a favor de unos u otros centros de decisión entre cuantos integran la articulación territorial diseñada en el título octavo de la Constitución ${ }^{22}$.

${ }^{21}$ Así, por ejemplo, STC 152/1998.

22 SSTC 206/1997 y 239/2002. 
Desde luego, la dicción literal de la mayoría de los principios rectores apoya esta concepción. En efecto, casi todos ellos están dirigidos a todos los poderes públicos, que no solo resultan vinculados a las metas y obligaciones que dichos principios imponen, sino que, además, pueden servirse de ellos como normas habilitadoras para realizar sus propias políticas protectoras. Son, pues, disposiciones de carácter horizontal que se proyectan sobre el ejercicio de la competencia, pero que no alteran la titularidad de la competencia establecida en la Constitución y en los estatutos de autonomía. No solo vinculan al Estado sino también a las comunidades autónomas y los entes locales. Todas estas entidades territoriales deberán actuar conforme a los principios, pero no pueden utilizarlos para incrementar el propio poder a costa del que corresponde a otras.

Conforme a este criterio, los principios actuarían diversamente en función de las competencias que corresponden a las distintas entidades territoriales. Por ejemplo, el grado de vinculación, y de habilitación, que corresponde a cada uno de los entes territoriales no es el mismo en sanidad, donde el Estado cuenta con la capacidad de dictar las bases y llevar a cabo la coordinación (art. 149.1.16 CE), que en medio ambiente, donde la entidad central dispone de la competencia básica, pero se admite que las comunidades autónomas establezcan medidas adicionales de protección (art. 149.1.23 CE). En este último supuesto, dichas entidades territoriales disponen de más atribuciones, ya que pueden interferir en las competencias de la entidad central, siempre que dicten medidas de protección y estas sean más elevadas que las del Estado.

El Tribunal Constitucional sigue reiterando este criterio. Ahora bien, en algunas ocasiones se ha servido de los principios rectores como argumento para interpretar de manera generosa las competencias del Estado, en detrimento de las reconocidas a las comunidades autónomas.

A veces, el Tribunal ha utilizado los principios para ampliar las atribuciones que corresponden al Estado en virtud de títulos horizontales, como es la regulación de las condiciones básicas que garanticen la igualdad de todos los españoles en el ejercicio de los derechos y el cumplimiento de los deberes constitucionales (art. 149.1.1 CE). En virtud de los principios, ha considerado adecuado que la entidad central ejerciera competencias en asuntos tales como la asistencia social ${ }^{23}$ o subvenciones ${ }^{24}$. En otros casos, el Tribunal Constitucional se ha servido de los principios para hacer una interpretación extensiva de otros títulos más específicos que corresponden al Estado, como son las bases y la coordinación general de la sanidad (art. 149.1.16 CE).

23 La STC 18/2016, FJ 7, recoge toda la jurisprudencia anterior.

24 STC 33/2014. 
La jurisprudencia sobre esta última materia ha sido especialmente polémica porque, en los últimos años, el Tribunal Constitucional ha modificado sustancialmente la extensión de las bases, lo que ha llevado a incrementar las competencias del Estado en detrimento de las que corresponden a las comunidades autónomas.

En un primer momento, el Tribunal Constitucional había concebido las bases en materia sanitaria como una regulación uniforme mínima y de vigencia en todo el territorio nacional. De esta manera, el Tribunal conseguía dos objetivos: de un lado, considera conforme a Constitución que las comunidades autónomas, en ejercicio de sus competencias y para cumplir el mandato establecido en el art. $43 \mathrm{CE}$, fueran más allá del mínimo impuesto por el Estado y mejoraran las prestaciones establecidas por dicha entidad territorial $^{25}$, de otro, obligaba a las comunidades autónomas a satisfacer, al menos, el nivel exigido por la entidad central. En aplicación de esta doctrina, por ejemplo, las SSTC 71/2014 y 85/2014 anularon las tasas conocidas como «euro por receta» impuestas por las comunidades autónomas de Cataluña y Madrid.

Como describe Luis Delgado (2019: 247), el problema aparece después de que el Estado rebajase el nivel de prestaciones mediante el Decreto Ley $16 / 2012^{26}$, que, entre otros extremos, privaba de la condición de asegurados a los mayores de 26 años, en ciertas circunstancias, y a los extranjeros en situación irregular. En la STC 139/2016, dictada sobre la constitucionalidad de dicha norma, el Tribunal Constitucional justifica esta reversión en la necesidad de garantizar la sostenibilidad del sistema nacional de salud, que impone a los poderes públicos la adopción de medidas de racionalización del gasto sanitario $^{27}$. Señala, además, que el art. $43 \mathrm{CE}$ y la articulación del derecho a protección de la salud requieren que el legislador estatal «regule las condiciones y términos en los que acceden los ciudadanos a las prestaciones y servicios sanitarios, respetando el contenido del mandato constitucional» (ibid.).

La reducción de los sujetos acogidos a las prestaciones no fue bien recibida por algunas comunidades autónomas, que reaccionaron con normas que

25 Sirva como ejemplo la STC 98/2004, en la que el Tribunal afirma que la competencia del Estado en sanidad consiste en una regulación uniforme mínima, sin perjuicio de las normas que sobre la materia puedan dictar las comunidades autónomas en orden a garantizar «una mejora en su ámbito territorial de ese mínimo común denominador establecido por el Estado».

26 El art. 1 de dicha norma modificaba el art. 3 de la Ley 16/2003, de 28 de mayo, de cohesión y calidad del Sistema Nacional de Salud.

27 FJ 8. 
iban más allá de la regulación del Estado, al ampliar la atención sanitaria a los extranjeros en situación irregular, por ejemplo. Como respuesta, el Gobierno nacional impugnó algunas de estas disposiciones (los decretos vasco y navarro, las leyes navarra y extremeña y el decreto ley valenciano) aduciendo que dichas disposiciones afectaban a materias de competencia exclusiva el Estado.

Subsiguientemente, el Tribunal, en la STC 134/2017, sobre el Decreto del Gobierno Vasco 114/2012, sobre régimen de las prestaciones sanitarias del Sistema Nacional de Salud en el ámbito de la Comunidad Autónoma de Euskadi, modifica de manera sustancial su anterior jurisprudencia acerca de las competencias de las comunidades autónomas en materia de sanidad.

Como ocurre con frecuencia, el Tribunal Constitucional reitera, en el FJ 5 de la sentencia, la concepción de los principios rectores de la política social y económica y la definición de las competencias de las comunidades autónomas sobre protección de la salud que habían aparecido en su anterior jurisprudencia y a la que ya se ha hecho referencia. Ahora bien, el Tribunal modifica sustancialmente su criterio anterior acerca de las competencias que corresponden al Estado en dicha materia. Señala, al respecto, que las comunidades autónomas deberán respetar «los límites y el alcance que las propias bases del Estado fijen, con fundamento en los intereses generales que aquél justifique ${ }^{28}$. De esta manera, como afirma el propio Tribunal, «se cierra toda posibilidad a las normas autonómicas de desarrollo para configurar un sistema de acceso a las prestaciones sanitarias que no atienda a los conceptos de asegurado o de beneficiario que han establecido las bases» (ibid.). Por esta razón, declara inconstitucionales las mejoras a las prestaciones sanitarias que incluía el decreto del Gobierno vasco.

Analizando esta decisión, Luis Delgado ha afirmado que las bases dejan, así, de operar como un mínimo común susceptible de mejora por las comunidades para pasar a ser un máximo que no puede ser ampliado ni mejorado por ellas (2019: 247).

La STC 134/2017 suscitó varios votos particulares. El primero de ellos subraya el cambio de criterio del Tribunal y mantiene la visión que, hasta entonces, había sostenido dicho órgano acerca de las bases como mínimo común mejorable. El voto de A. Narváez Rodríguez añade algo más, que es de interés para estas páginas. El magistrado argumenta que el Tribunal no debe alejarse de la anterior concepción de las bases como ordenación mediante mínimos porque ha de tener en cuenta también el conjunto de los principios constitucionales de orden material que la propia norma fundamental recoge, entre los que incluye los principios rectores de la política

28 FJ 5. 
social y económica. Por ello defiende que el máximo intérprete de la Constitución traslade al ámbito de la salud el mismo criterio que había aplicado al medio ambiente, esto es, que entre las diversas interpretaciones posibles de las reglas de distribución de competencias el Tribunal solo respalde aquellas que razonablemente permitan cumplir con los mandatos impuestos por los principios rectores.

Para el magistrado, tales principios son decisiones axiológicas jurídico-objetivas, por lo que se les debe dotar de la mayor fuerza normativa posible. Es cierto que dejan al legislador un amplio grado de libertad, pero esta libertad no solo debe corresponder al legislador del Estado, sino a todo legislador con competencias en la concreta materia.

En definitiva, el Tribunal Constitucional puede hacer más de lo que ha hecho recientemente a la hora de velar por el valor hermenéutico de los principios. Como afirma T. de la Quadra, debería respaldar la interpretación de las reglas de distribución de competencias que mejor permitan a los poderes públicos cumplir y alcanzar los objetivos de protección y mejora establecidos por los principios rectores (2017: 18). Y esta obligación se refuerza cuando las competencias que alegan las comunidades autónomas son, además, de naturaleza exclusiva.

En gran medida, la jurisprudencia del Tribunal Constitucional es consecuencia de otro problema más general, esto es, la rigidez con la que ha interpretado la distribución de competencias en nuestro ordenamiento. Quizá con la intención de garantizar la autonomía que el art. $2 \mathrm{CE}$ reconoce a las comunidades autónomas, la competencia de cada una de las entidades territoriales no solo se ha considerado indeclinable, sino también excluyente. $\mathrm{Su}$ ejercicio impide que las demás ejerzan autoridad sobre el mismo ámbito de la realidad (Biglino, 2007: 176-179). En nuestro ordenamiento no existen competencias complementarias, o de apoyo, tal y como sin embargo reconoce el art. 6 del TFUE con respecto a la Unión. Recordemos que, según este precepto, los países conservan sus competencias, pero las instituciones europeas pueden llevar a cabo acciones con el fin de apoyar, coordinar o complementar la acción de los Estados miembros en asuntos tales como protección y mejora de la salud humana, la cultura, el turismo, la educación, la formación profesional y la juventud, esto es, bienes muy próximos los protegidos por nuestros principios rectores.

Es evidente que el Tribunal Constitucional no puede ignorar las peculiaridades de nuestro reparto competencial. Ahora bien, podría interpretarlo de manera que no agravase la rigidez que lo caracteriza. Sería posible, por ejemplo, que siguiese sus propias máximas excluyendo los principios a la hora de delimitar competencias. Y, desde luego, podría aplicar los principios rectores de manera 
que, en vez de disminuir las competencias que las propias comunidades autónomas tienen garantizadas, permitiera a dichas entidades territoriales mayor libertad a la hora de diseñar sus propias políticas. Es cierto que, en muchas ocasiones, dicha libertad estará condicionada por principios que las comunidades autónomas han de respetar, como es el equilibrio presupuestario, la sostenibilidad del sistema de salud, etc., materias en las que el Estado tiene mucho que decir. Pero el principio de autonomía y una correcta comprensión de los principios deberían permitir que las comunidades autónomas, dentro de sus disponibilidades financieras y conforme al criterio de sus legisladores, cooperasen en la satisfacción de las obligaciones que el Estado social impone a los poderes públicos.

\section{PRINCIPIOS RECTORES Y PONDERACIÓN EN DERECHOS}

Queda una última cuestión por analizar y que, como antes se señalaba, se refiere al peso que deben tener los principios en la ponderación que el Tribunal Constitucional debe hacer cuando hay en juego diferentes derechos y bienes constitucionales.

Por razones de espacio no puedo entrar a analizar aquellos casos en los que el Tribunal Constitucional ha logrado proteger los principios rectores vinculándolos con los derechos fundamentales. Díaz Crego (2012: 51-52) ha demostrado que, a través de esta vía, el Tribunal Constitucional ha logrado salvaguardar el derecho a la conciliación y a la vida familiar, además de hacer frente a múltiples discriminaciones laborales, estableciendo conexiones con la igualdad o con la tutela judicial efectiva. Atención especial merece la protección a la salud, que ha resultado fortalecida gracias a su vinculación con el derecho a la integridad física ${ }^{29}$. Tampoco cabe desconocer que, en determinadas ocasiones, el Tribunal ha logrado proteger la calidad ambiental vinculándola con la inviolabilidad del domicilio (Simón, 2012: 175). Es cierto que, para algunos, esta protección es más limitada que la ofrecida por el Tribunal Europeo de Derechos Humanos (Cubero, 2017: 118 y ss.). Pero también es verdad que, a través de este camino, el Tribunal ha logrado proteger, mediante el recurso de amparo, principios que en nuestro ordenamiento no son, ni siquiera, derechos subjetivos.

El Tribunal Constitucional ha resumido su orientación en el FJ 2 de la STC 105/2017, cuando afirma:

El hecho de que los principios no sean, en sí mismos, susceptibles de amparo, no supone su necesaria irrelevancia en ese tipo de procesos constitucionales. Lo que

29 La STC 160/2007 cita la jurisprudencia precedente sobre el tema. 
no puede hacer el Tribunal es atender a las alegaciones que se encuadren en los principios de modo autónomo y privativo, desconectados pues de un derecho fundamental.

Hay, sin embargo, otro aspecto de la eficacia interpretativa de los principios que ha revestido menos interés, aunque quizá tenga mayor importancia. Se refiere a la manera en que los principios han de influir cuando el Tribunal debe resolver casos de conflicto entre derechos o entre derechos y otros bienes constitucionales.

No se trata, en este caso, de la potencialidad de los principios rectores como normas parámetro que puedan motivar la declaración de inconstitucionalidad, asunto que se trató en el tercer apartado de este trabajo; tampoco, como acabo de señalar, de la conexión mediata o inmediata entre derechos fundamentales y principios rectores. Se trata de la potencialidad de los principios como normas de interpretación en caso de que la justicia constitucional se encuentre ante la necesidad de resolver conflictos entre derechos subjetivos o de contradicción entre derechos y otros principios y valores constitucionales. También en estos casos, el Tribunal Constitucional debería tener en cuenta las previsiones del capítulo tercero del título primero porque, como indica el art. 53.3 CE, estos no solo informan al legislador sino también la práctica judicial. En estas ocasiones, en las que otros derechos y bienes constitucionales están en equilibrio, el Tribunal debería inclinar la balanza en favor de la interpretación más favorable a los principios rectores.

La jurisprudencia del máximo intérprete de la Constitución a la hora de cumplir esta tarea podría ir más allá de lo que ha sucedido hasta ahora. Un buen ejemplo de ello es la reciente STC 118/2019. Esta decisión es consecuencia de una cuestión de inconstitucionalidad sobre art. 52 d) del texto refundido de la Ley del Estatuto de los Trabajadores. Dicho precepto, ahora derogado, preveía la extinción del contrato de trabajo por causas objetivas, entre las que se incluían las faltas de asistencia al trabajo, aún justificadas pero intermitentes, cuando estas se produjesen por enfermedades que no fueran graves y siempre que se dieran determinadas circunstancias ${ }^{30}$. Ante el despido de una trabadora por esta causa, un juzgado de lo social elevó ante el Tribunal Constitucional sus dudas acerca de la compatibilidad de dicho precepto con los derechos a la integridad física (art. 15 CE), al trabajo (art. 35.1 CE) y a la

30 El precepto, en efecto, exigía que dichas faltas deberían alcanzar el $20 \%$ de las jornadas hábiles en dos meses consecutivos siempre que el total de faltas de asistencia en los doce meses anteriores alcanzase el $5 \%$ de las jornadas hábiles, o el $25 \%$ en cuatro meses discontinuos dentro de un período de doce meses. 
protección de la salud (art. 43.1 CE). El Tribunal Constitucional desestima la cuestión porque considera que no ha habido vulneración de ninguno de estos preceptos.

Las partes más sustantivas de la sentencia son aquellas en las que se ponderan la libertad de empresa y el derecho al trabajo, tema que escapa al objetivo de estas páginas. Con respecto a la salud, el Tribunal reitera su jurisprudencia en que la configura como un derecho vinculado a la integridad física. Ahora bien, añade que una determinada actuación empresarial en relación con las bajas por enfermedad del trabajador solo podría afectar al ámbito protegido por el art. $15 \mathrm{CE}$ si existiese un riesgo relevante de que la lesión pudiera llegar a producirse, «es decir, cuando se generara un peligro grave y cierto para la salud del afectado $»^{31}$, circunstancia que el Tribunal no advierte que concurra en el supuesto analizado. Al hacer esta afirmación, no parece que el Tribunal Constitucional tenga en cuenta que el proceso en que dicta sentencia no es de amparo, sino de constitucionalidad. En este caso, no se trata de verificar si la empresa vulnera el derecho a la salud, sino si el legislador, al prever como causa justa de despido la ausencia por enfermedad no grave pero intermitente, está respetando la salud de los trabajadores.

El Tribunal analiza, después, la presunta contradicción del art. 52 d) del texto refundido de la Ley del Estatuto de los Trabajadores con el derecho a la protección de la salud que reconoce el art. 43.1 CE. También en este caso descarta la inconstitucionalidad.

El Tribunal, tras reiterar que los principios no son normas meramente programáticas ni están vacías de contenido, vuelve a subrayar su carácter vinculante sobre todos los poderes públicos. Ahora bien, acto seguido resta fuerza a esta afirmación, porque reduce el derecho a la protección de la salud a las obligaciones que el segundo párrafo del art. $43 \mathrm{CE}$ impone al legislador, esto es, la regulación de las condiciones y términos en los que acceden los ciudadanos a las prestaciones y servicios sanitarios ${ }^{32}$. Esta visión del contenido del principio se apoya, exclusivamente, en lo que había dicho el Tribunal en la STC 139/2016, que, como se ha examinado en páginas precedentes, versaba sobre un problema muy distinto, como es la reducción de prestaciones operada por el Decreto Ley 16/2012.

Es cierto que el art. 43.2 CE recoge, literalmente, los contenidos que cita el Tribunal. También es verdad que el primer apartado del precepto es bastante genérico, porque solo reconoce el derecho a la protección de la salud. Ahora bien, también se puede interpretar que las obligaciones que dicho artículo impone a los

31 FJ 4. El Tribunal se remite a las SSTC 221/2002, 220/2005 y 62/2007.

32 FJ 5. 
poderes públicos consisten en algo más que las prestaciones sanitarias. De hecho, como acabamos de mencionar, el propio Tribunal ha añadido muchos más contenidos en virtud de la relación que existe entre este la salud y el art. $15 \mathrm{CE}$.

El Tribunal analiza uno de los argumentos formulados en el auto de planteamiento de la cuestión, en virtud del cual el temor de los trabajadores a ser despedidos puede empujarles a acudir al trabajo pese a sufrir una enfermedad, con riesgo para su salud. El Tribunal reconoce, además, que ese riesgo puede darse. Pero, a pesar de ello, considera que la regulación del legislador no desprotege la salud de los trabajadores, sino que simplemente «se limita a regular la posibilidad de que el empresario extinga el contrato de trabajo por faltas de asistencia al mismo». Dicho de otro modo, «el legislador identifica la excesiva morbilidad intermitente como una de las causas principales de ausencias al trabajo» (ibid.).

El argumento para confirmar la constitucionalidad de la norma es un tanto paradójico: es evidente que el legislador ha optado por proteger los intereses de la empresa frente a las bajas intermitentes, pero no está nada claro, ni el Tribunal justifica, que esta opción sea constitucional. El Tribunal no tiene en cuenta, entre otras cosas, el chilling effect que puede tener la norma cuestionada, al inhibir a los trabajadores de ejercer un derecho legítimo (como es una baja justificada por enfermedad) ante el temor a una consecuencia tan grave como es el despido. En definitiva, hay argumentos para poner en duda la constitucionalidad de una norma que quizá no proteja de manera adecuada ni la salud de los trabajadores enfermos ni la de quienes conforman su entorno laboral, que también podrían verse afectados por contagio. Habría sido conveniente que el Tribunal se tomara ese razonamiento algo más en serio y le hubiera dado la respuesta que merece.

Los votos particulares de los magistrados Valdés Dal-Ré y Balaguer Callejón contradicen la opinión de la mayoría señalando que debería haberse dado prioridad al derecho al trabajo y al derecho a la salud. Ambos coinciden en señalar que el Tribunal no ha ponderado adecuadamente los derechos y principios en juego. En este aspecto, hay que dar la razón a los magistrados que disienten del pleno.

Al final del último fundamento jurídico, el Tribunal resume la forma en que ha ponderado los derechos en conflicto. Tras afirmar que, efectivamente, el despido por enfermedad intermitente limita el derecho al trabajo, concluye que no es inconstitucional porque la medida persigue una finalidad legítima, que consiste en evitar el incremento de los costes que las ausencias del trabajo suponen para la empresa y la defensa de la productividad.

Frente a este razonamiento es posible utilizar algunos argumentos. En primer lugar, cabe recordar que la libertad de empresa que garantiza la 
Constitución es un derecho de libertad y de igualdad que conlleva un haz de facultades, que van desde la creación, pasando por la organización y el funcionamiento, hasta llegar a la facultad de decidir el cese de la empresa (Aragón y Losada, 2014: 35-39). Ahora bien, ni el legislador, al elaborar la ley, demuestra que el absentismo por enfermedad intermitente esté poniendo en riesgo esa libertad, ni el Tribunal explica los motivos que le llevan a incluir la productividad, o beneficio económico, en el contenido de la libertad de empresa. En segundo lugar, es preciso constatar que el Tribunal Constitucional omite la protección de la salud en su ponderación. Es verdad que esta obligación, en muchos casos, no es un derecho subjetivo. Ahora bien, eso no supone que no deba tenerse en cuenta como criterio interpretativo.

En el caso analizado el conflicto es entre libertad de empresa y derecho al trabajo, que gozan de similares garantías en nuestro ordenamiento. Estaba en juego, además, la salud de los trabajadores, proyección de un principio rector que impone obligaciones a los poderes públicos, entre los que se incluye el legislador y el propio Tribunal Constitucional, por lo que no debe ser omitido a la hora de ponderar derechos, principios y valores. No es cuestión de entrar a analizar, ahora, si la decisión final debería haber sido distinta. Merece solo la pena observar que el Tribunal Constitucional habría debido incluir la protección de la salud en su razonamiento y valorar su influencia sobre los dos derechos constitucionales en juego.

El Comité de Derechos Económicos, Sociales y Culturales de la ONU, en su sexto informe sobre España ${ }^{33}$, expone sus reservas ante la escasa eficacia jurídica que, en nuestro país, siguen teniendo los derechos reconocidos en el Pacto Internacional de Derechos Económicos, Sociales y Culturales, ratificado por nuestro país hace más de cuarenta años. Entre los principales motivos de preocupación figura que estos derechos sigan siendo meros principios rectores de la política social y económica que únicamente puedan ser invocados cuando hayan sido desarrollados legislativamente o en relación con otros derechos que cuentan con mayor protección, tal como el derecho a la vida. Por esta razón, recomienda que España tome las medidas legislativas pertinentes para promover la aplicabilidad de todos los derechos consagrados en el Pacto en todos los niveles del sistema judicial, incluso mediante el recurso de amparo.

Desde estas páginas, no es posible analizar esta recomendación con detalle. Conviene destacar, sin embargo, que alguno de sus objetivos podría

33 Comité de Derechos Económicos, Sociales y Culturales. Sexto informe periódico que España debia presentar en 2017 en virtud de los artículos 16 y 17 del Pacto, 9-9-2017. Disponible en: https://bit.ly/3gvnM3k. 
alcanzarse si se potenciara la eficacia de los principios rectores. Como ya se ha señalado, no son meras normas programáticas, sino que son normas jurídicas dotadas del máximo rango. Aunque no contengan reglas, son parámetro de constitucionalidad de la ley, ya que vinculan al legislador. Es cierto los principios tienen distintos grados determinación, por lo que la libertad del legislador variará según lo que imponga cada principio en concreto. Ahora bien, ni el legislador debe ignorarlos ni pueden ser preteridos por el Tribunal Constitucional a la hora de velar por la constitucionalidad de las leyes y de interpretar la norma fundamental y el resto del ordenamiento jurídico.

Hay muchas voces críticas que tildan de caduca la Constitución y que, por ello, proponen reformarla. Es posible que una visión más generosa de la eficacia de los principios rectores de la política social y económica hubiera servido para amoldar nuestra norma fundamental a las nuevas demandas y cumplir, de paso, con nuestras obligaciones internacionales. En cualquier caso, quizá no sea demasiado tarde para intentarlo.

\section{Bibliografía}

Aguiar de Luque, L. (1987). El Tribunal Constitucional y la función legislativa: el control del procedimiento legislativo y la inconstitucionalidad por omisión. Revista de Derecho Politico, 24, 9-30.

Aragón, M. (1988). La eficacia jurídica del principio democrático. Revista Española de Derecho Constitucional, 24, 9-45.

- (1989). Constitución y democracia. Madrid: Tecnos.

Aragón, M. y Losada González, H. (2014). La libertad de empresa. Revista del Ministerio de Empleo y Seguridad Social. Derecho del Trabajo, 108, 17-40.

Biglino Campos, P. (2007). Federalismo de integración y de devolución. El debate sobre las competencias. Madrid: Centro de Estudios Políticos y Constitucionales.

(2016). La democracia en Atenas. Crisis económica y legitimidad democrática en la Unión Europea. En F. Balaguer Callejón y J. Tudela Aranda (coords.). Estudios en Homenaje al profesor y magistrado Luis Ortega Álvarez (pp. 65-81). Cizur Menor: Thomson Reuters, Aranzadi. Disponible en: https://bit.ly/2AieI1b.

Cubero Marcos, J. I. (2017). La vis expansiva de los derechos fundamentales y su incidencia en la configuración y exigibilidad de los derechos sociales. Revista Española de Derecho Constitucional, 110, 105-140. Disponible en: https://doi.org/10.18042/cepc/redc.110.04.

De Otto, I. (1989). Derecho Constitucional. Sistema de Fuentes, Barcelona: Ariel.

Delgado del Rincón, L (2019). El derecho a la asistencia sanitaria de los extranjeros: limitaciones y problemas competenciales. Valencia: Tirant lo Blanch.

Díaz Crego, M. (2012). Derechos sociales y amparo constitucional. Revista Vasca de Administración Pública, 94, 17-57. 
Dicey, A. V. y Wade, E. C. S. (1987). Introduction to the study of the law of the constitution. London: McMillan.

Garrido Falla, F. (1980). Art. 53. En F. Garrido Falla (dir.). Comentarios a la Constitución. Madrid: Civitas.

Jiménez Campo, J. (1999). Derechos fundamentales. Concepto y garantías. Madrid: Trotta.

Kelsen, H. (1995). Teoría General del Derecho y del Estado. México, DF: Universidad Nacional Autónoma de México.

Medina Guerrero, M. (2015). Derecho a la vivienda y desahucios: la protección del deudor hipotecario en la jurisprudencia del TJUE. Teoria y Realidad Constitucional, 36, 261-282. Disponible en: https://doi.org/10.5944/trc.36.2015.16068.

Prada Fernández de Sanmamed, J. L. (2003). Revisión de los principios rectores de la política social y económica y de su actual realidad jurídico-constitucional. Revista de Estudios Políticos, 122, 269-316.

Ponce Solé, J. (2017). Reforma constitucional y derechos sociales: la necesidad de un nuevo paradigma en el Derecho público español. Revista Española de Derecho Constitucional, 111, 67-98. Disponible en: https://doi.org/10.18042/cepc/redc.111.03.

Quadra-Salcedo Janini, T. de la (2017). El Estado autonómico social. El efecto de irradiación de los derechos sociales sobre el modelo constitucional de distribución de competencias. Revista General de Derecho Administrativo, 46, 1-38.

Rodríguez de Santiago, J. M. (2018). Art. 53. La forma de vincular de los preceptos del capítulo tercero del título primero de la Constitución española. En M. Rodríguez-Piñero y Bravo Ferrer y E. Casas Baamonde (dirs.). Comentarios a la Constitución española. XL aniversario (pp. 1488-1493). Madrid: Boletín Oficial del Estado.

Rubio Llorente, F. (1984). Prólogo. En E. Alonso García. La interpretación de la Constitución. Madrid: Centro de Estudios Constitucionales.

Serrano, J. L. (1987). Algunas hipótesis sobre los principios rectores de la política social y económica. Revista de Estudios Politicos, 56, 95-120.

Simón Yarza, F. (2012). El llamado derecho al medio ambiente: un desafío a la teoría de los derechos fundamentales. Revista Española de Derecho Constitucional, 94, 153-179. 